\title{
A Survey of Personality Trait Perceptions in Leadership Promotions in the Greek Armed Forces
}

\author{
John A. Paravantis* \\ Department of International and European Studies, University of Piraeus \\ 80 Karaoli \& Dimitriou Street, 18534 Piraeus, Greece \\ E-mail:.jparav@unipi.gr \\ Nikoletta V. Kontoulis \\ Department of International and European Studies, University of Piraeus \\ 80 Karaoli \& Dimitriou Street, 18534 Piraeus, Greece \\ E-mail: nicole.kontoulis@gmail.com \\ Ioanna Iliadi \\ ArmyVoice.gr \\ E-mail: ioanna.iliadi@gmail.com
}

\begin{abstract}
Army personnel perceives character and personality traits as playing an important role in promoting high ranking officers to leaders. Whether the different categories of army personnel perceive the relative importance of such traits similarly is a question of significance for the morale, cohesiveness and efficiency of the armed forces. This paper addresses the documented scarcity of empirical research on such perceptions. The research literature on leadership traits was reviewed with emphasis on the armed and security forces. An online questionnaire was designed and 2702 responses of Greek armed and security forces personnel were collected, including 947 officers, 534 non-commissioned officers, 531 veterans, 81 security forces personnel, and 609 civil personnel. An $86.3 \%$ of respondents felt that leadership promotions failed to consider appropriate character and personality traits such as crisis management, integrity, perception, meritocracy, strategic proficiency, bluntness, and impartiality. Cooperation with the political leadership was considered unduly important. Cluster Analysis confirmed by Discriminant Analysis rendered four clusters: politically non-aligned; religious; authority-oriented conformist; and dissatisfied nonconformist. To maintain the morale and cohesiveness of military personnel, it was advised that the promotion to leaders of the armed and security forces be enriched with distilled elements of wisdom from the perceptions of all personnel clusters.
\end{abstract}

Keywords: Leadership, armed forces, personality traits, Cluster Analysis

DOI: $10.7176 / \mathrm{JRDM} / 63-04$

Publication date:March $31^{\text {st }} 2020$

\section{Introduction}

The military and the concept of leadership with the accompanying character (i.e. inner) and personality (i.e. outer) traits have been inseparable (Navy Department, 1913; Wong, Bliese \& McGurk 2003). The promotion of high ranking officers to leaders is done by promotion boards, oftentimes with input by political leadership. Two related questions arise: (a) Which character and personality traits are perceived by army personnel to play an important role in promoting high ranking officers to leaders? (b) Do the different categories of armed forces personnel perceive the relative importance of these traits similarly? These questions are important for the morale, cohesiveness and efficiency of the armed forces.

There is a documented scarcity of research findings on leaders of the armed forces and their character and personality traits (Keller 2014; Nichols \& Cottrell 2014). Furthermore, to the knowledge of the authors of this paper, there has been limited research on the perception of such traits important for leadership promotions by the personnel of armed forces. This research aims to address this lack of knowledge by analyzing a large survey of personnel in the armed and security forces of Greece.

In the rest of this paper, Section 2 contains the literature review of leadership trait research and related surveys; Section 3 presents the research questions, outlines the collected data, and mentions the statistical techniques and tools used; Section 4 presents the results of the descriptive and multivariate analysis and concludes with discussion points; finally, Section 5 rounds up the paper with the conclusions.

\section{Literature review}

\subsection{Military leadership}

Defining leadership is as demanding as defining beauty (Bennis and Nanus 1985), with no clear definition (Fairholm 2002) and no universal concept. There exist 221 different definitions that share much similarity among 
them (Rost 1993). Most of them refer to character and personality traits; abilities; skills; and behaviors. A working definition is provided by Northouse (2016): leadership is a process whereby an individual (i.e. the leader) influences a group of individuals (i.e. the subordinates) to achieve a common goal.

Leadership and management are related, but distinct concepts (Begeç 2013), with leadership requiring attributes and characteristics above and beyond those of management (Sing, Tiwary \& Mishra 2015; Hogan \& Kaiser 2005). Leaders solve problems by innovating (Johnson 2014) and creating a motivational environment for their subordinates (Nickels, McHugh \& McHugh 2010). Such leadership continues to be a key pillar of the military (Wong, Bliese \& McGurk 2003).

Each profession has its own culture and its own unique leadership aspects (Wong, Bliese \& McGurk 2003). The military consists of diverse organizations, roles, cultures, people and encompasses three professions (army, maritime and air force). Military leadership is "an art, a creative activity based on character, ability and mental power" called into service under both peace and war (Keller 2014). During war, the military becomes a chaotic organization that does not comply with the bureaucratic model and requires absolute obedience (Keller 2014). Nevertheless, military leadership has been socially constructed as a positive aspiration (Reed \& Bullis 2009).

The leadership vision of the US Army is encapsulated in the phrase: "We are about leadership; it is our stockin-trade, and it is what makes us different" (Wong, Bliese \& McGurk 2003). For the US Army (2006) leadership is "the process of influencing people by providing purpose, direction, and motivation while operating to accomplish the mission". Reflecting on military leadership into the 21 st century, a retired US Lieutenant General has argued that the "desirable qualities and skills of a leader may vary a bit, but the basic formula for leader success has changed little in 2000 years" with the purpose being "to get the job done" (Ulmer 1998). Sing, Tiwary and Mishra (2015) have also defined military leadership as the "art of getting things done" with a combination of example, persuasion and compulsion that motivate subordinates to carry out their duties. A real leader must be "an agent for change, an inspirer and developer who is able to show the way forward, integrate people and ideas and be prepared to instigate rapidly the most effective option".

\subsection{Military leadership traits}

Definitions of leadership like those used by the US Army, mirror definitions of leadership normally found in the general leadership literature (Hannah \& Sowden 2012) and are linked to unique character and personality traits (Day et al. 2014; Khan, Nawaz \& Khan 2016; Allen 1998). Zaccaro, Kemp and Bader (2004) defined traits as "relatively stable and coherent integrations of personal characteristics ... including personality, temperament, motives, cognitive abilities, skills, and expertise".

While the ultimate objective of military leadership is the successful accomplishment of missions (US Army 1965), its effectiveness depends on many character and personality traits of the leaders (Wisecarver et al. 2011). Zaccaro, Klimoski and Gade (1999) presented four core dimensions of leadership: values, attributes, skills and actions. Sing, Tiwary and Mishra (2015) highlighted three main areas of leadership qualities that are developed with experience: approach to people; approach to tasks; and individual orientation.

Looking into the literature for specific traits, physical fitness, intelligence, emotional stability and good communication skills have been proposed as abilities of any army officer (Sing, Tiwary \& Mishra 2015). Trustworthiness has been considered cornerstone of military leadership (Ivancevich, Konopaske \& Matteson 2007). A strong character and the ability to influence others across different types of missions have been reported as characteristics common among the best officers (Wisecarver et al. 2011). Finally, authority, responsibility and chain of command have been regarded as important dimensions of military leadership (Özlen \& Zukic 2013).

The US Army (2006) pictured an army leader as a leader of: character, with values, empathy, and a "warrior ethos"; physical presence, with military bearing, physical fitness, confidence, and resilience; intellectual capacity. Hardaway (2008) argued that the US Army develops strategic thinkers capable of leading decisively in complex and adaptive environments. Zaccaro, Klimoski and Gade (1999) summarized the contribution of several military and civilian leadership researchers in seven key themes: leader effectiveness; leader potential; leadership development; management of change; leader performance under adversity; development of subordinate personnel; and leadership of retention.

Erasmus and Uys (2012) compared leadership development practices among Germany, the United Kingdom and South Africa, and proposed a five-point model including; convergent leadership; political participation; superior selection; interventions for leadership character development; and military leadership institution. Keller (2014) underscored that personality and trust are considered the basis of success in the German armed forces. Begeç (2013) examined the education and training of future leaders in the Turkish armed forces at three levels: military high schools; war schools; and military academies (for senior personnel). Begeç concluded that for a leader to be effective, he or she must be accepted by subordinates. Özlen and Zukic (2013) examined the armed forces of Bosnia and Herzegovina, polling full-time soldiers with a thirty-six question questionnaire, concluding that military leaders were considered: charismatic; conscientious; suitable for leadership; agreeable; extroverted; stereotyped; decisive; and honest. Singh, Tiwary and Mishra (2015) offered intelligence on how leadership is 
perceived within the armed forces of India, the UK, the US and Canada. Leadership qualities were grouped into three areas: approach to people; approach to tasks; and individual orientation. It was concluded that initiative and confidence were vital for leadership success.

Boe and Holth (2015) investigated possible correlations between inspiration and motivation in leadership. Based on hypotheses derived from previous studies, they used two questionnaires to measure personality traits and leadership style in the Norwegian Army. It was found that gifted leaders "inspire, communicate their vision, and are committed to relationships". "Self-knowledge, positive emotions, and gregariousness" were found to be important for good leadership. Based upon that survey, Boe and Bang (2017) examined whether there are specific character strengths that are considered more important than others for a military officer to succeed in a leadership position in the Norwegian military forces. A total of 21 experienced military officers were asked to judge the importance of character strengths via questionnaires. The 13 character strengths that were selected as the most important were: leadership; teamwork; open-mindedness; integrity; persistence; bravery; curiosity; love of learning; social intelligence; fairness; perspective; creativity; and self-regulation.

Nichols and Cottrell (2014) researched the traits that subordinates desired in their leaders. First, 116 participants (including 71 men and 45 women) were asked to rate the prototypicality, desirability, and supervisor ratings of the following individual traits: agreeableness; conscientiousness; emotional stability; extraversion; openness to experience; assertiveness; confidence; courage; compassion; cooperativeness; supportiveness; trustingness (i.e. believing in the honesty and reliability of others); and trustworthiness. Then, 51 participants (including 26 men and 25 women) rated the desirability of these traits for 12 different leaders. Finally, 413 participants (including 199 men and 212 women) were asked to prioritize traits and build their ideal leaders. It was concluded that trustworthiness and intelligence were commonly desired traits, depending on the level of leadership.

Accepting that no personality traits may predict leadership success with certainty (Asrar-ul-Haq and Anwar 2018; Pierce and Newstrom 2006), this research investigates those character and personality traits that are considered to play an important role in leadership promotions in the Greek armed forces.

\section{Research questions, data collection and statistical techniques}

This research aims to supplement the limited empirical research that exists on the questions: (1) What are the perceptions of army and security forces personnel regarding the character and personality traits that are taken into account when their top leaders are chosen? (2) Do different groups of employees in the armed and security forces perceive the relative importance of these traits differently? Taking the results of this research into consideration may enable the Greek armed forces redesign the leadership promotion process so that its personnel is happier and better motivated.

Of the three levels of military leadership (direct, organizational and strategic; US Army, 2006), this research concerns itself with the top level. The empirical data analyzed were collected via an online questionnaire that was designed specifically for this study, and was open to personnel of the armed and security forces of Greece. The questionnaire included 32 questions which asked respondents to rate the character and personality traits that (1) were actually considered (referred to as the descriptive part), and (2) should be considered (normative part) when promoting the top leaders of armed and security forces. Ratings were on a 5-scale Likert type response. Variable names and definitions, including professional affiliation labels and leadership (character and personality) trait ratings, are shown in Table 1.

Descriptive statistical techniques, Cluster Analysis and Discriminant Analysis were used. Descriptive analyses and figures were carried out with Minitab version 18; Cluster and Discriminant analyses were run on IBM SPSS version 25.

\section{Results}

A total of 2702 responses were collected. Slightly over one third (947 cases or $35.05 \%$ of the total) were by officers; about one fifth were by non-commissioned officers (534 or 19.76\%); another one firth by veterans (531 or 19.65\%); and a small number $(81$ or $3 \%)$ by members of the security forces. The rest $609(22.54 \%)$ came from civil personnel of the armed or security forces. Of the 2702 respondents, $94.9 \%$ (2564) were male, and 5.1\% (138) were female. The gender breakdown by professional affiliation is shown in Table 2 . The civil personnel and security classes had the biggest percentage of females (11.49 and 8.64\% correspondingly).

Of the 2702 respondents, $398(14.7 \%)$ provided an e-mail address, more male (14.9\%) than female $(12.3 \%)$. Breaking down the e-mail responses by professional affiliation, showed that veterans were the most likely to provide an email address $(22.98 \%)$, while officers were the least likely to provide an email address $(11.51 \%)$. Although these discrepancies may indicate that older individuals were less likely to have an e-mail, it could be that veterans were less reluctant to reveal their identity.

\subsection{Normative and descriptive trait ratings}

Attention how shifts to the ratings of traits considered in promoting the top leadership of armed and security forces. 
The percentage of non-responses to each question (total and per rank and professional affiliation) did not reveal any systematic association with the provision of e-mail. It was concluded that the indirect revelation of a respondent's identity (though the e-mail) did not introduce any bias to the responses.

As aforementioned, each respondent rated two groups of character and personality traits: one documenting the normative view, i.e. the perceptions of the respondents on how different traits should be used by promotion boards when selecting the top leadership of armed and security forces; and a second documenting the descriptive view, i.e. the opinion of the respondents on how different traits were used in practice by promotion boards when selecting the top leadership of armed and security forces. The average values of each trait rating, normative and descriptive, along with the difference of the two scores are shown in Table 3.

On the one hand, respondents thought that crisis management (4.91), integrity (4.90), perception (4.84), meritocracy (4.83), strategic proficiency (4.77), bluntness (4.76), and impartiality (4.73), were the traits that should be taken into account by promotion boards (normative). On the other hand, respondents thought that cooperation with the political leadership (4.46) was the trait that was mostly considered in practice by promotion boards (descriptive). Interestingly, cooperation with the political leadership was the trait that was regarded as the least important in a normative sense (3.05). Also, while bluntness had a very high average normative rating (4.76), it was considered the least taken into account in practice (2.02).

A comparison of the average normative and descriptive ratings is shown in Figure 1, which charts the difference (normative minus descriptive average ratings) sorted by decreasing value. At the left end of the bar chart, posing problems bluntly was the trait with the biggest difference between normative (4.76) and descriptive (2.02) ratings, showing that bluntness was among the traits considered essential for a leader, but taken into account the least during actual promotions. At the right end of the bar chart, cooperating with the political leadership was the only trait that scored higher in the descriptive than in the normative assessment, showing how the willingness to work closely with the political leadership of the armed and security forces, was very important during the promotion process, although (in the opinion of the respondents) it should not be.

A view to how the normative and descriptive average ratings were related is given by the scatterplot of Figure 2. The thick black dotted line has a 45 degree (i.e. 1:1) slope, indicating the locus of points with equal normative and descriptive ratings. Points that lie below the dotted line had a normative rating bigger than their descriptive one; points that lie above the dotted line had a descriptive rating bigger than their normative one. So, the location of the outlying point that represents the trait of cooperation with the political leadership (at the upper left of the scatterplot) illustrates that this was the trait that the respondents thought was very important during the promotion process although it should not have been. The personal appearance trait point (at the lower left of the scatterplot) was nearer the dotted line, showing that appearance was considered moderately important by the respondents, and was afforded about the same amount of attention by promotion boards. Many of the points that cluster at the lower right of the scatterplot indicate traits (such as bluntness, impartiality and meritocracy) that should be regarded as very important, but were not during promotions. Religiosity, NATO and other international experience, as well as communication skills are in the lower center of the scatterplot, indicating traits that respondents thought should be regarded as having a moderate amount of importance, but were treated as somewhat less important by promotion boards.

In Table 4, the average ratings of the trait variables are broken down by rank and professional affiliation of the respondents, with the last column displaying the statistical significance of either an ANOVA or a Welch test (depending on the results of a Levene's test of homogeneity of variance) among the rank and professional affiliation groups. Although many differences among the ranks and professional affiliations were statistically significant, the actual ratings were not that different in most cases. Being willing to cooperate with the political leadership and being religious were the only traits with both normative and descriptive ratings statistically different among the groups at a $95 \%$ confidence level $(\mathrm{p} \leq 0.05)$; having NATO and other international experience and being experienced with all administration levels were the traits with both normative and descriptive ratings statistically different among the groups at a $90 \%$ confidence level $(\mathrm{p} \leq 0.1)$.

Crises management had the biggest normative score across all categories, with perception, meritocracy, bluntness, integrity, strategic skills, and impartiality being also important from a normative point of view. Cooperating with the political leadership had the lowest normative score and the highest descriptive score in almost all categories. Officers and civil personnel considered NATO and international experience to be the second most important trait descriptively, while non-commissioned officers, veterans and members of the security forces regarded being nonpartisan as the second most important skill descriptively.

\subsection{Cluster analysis}

Cluster Analysis (CA) was run next, to discover groups of like-minded respondents. On the issue of sample size, Formann (1984) as cited by Mooi and Sarstedt (2011), recommended a sample of at least $2^{\mathrm{m}}$ cases, where $\mathrm{m}$ equals the number of clustering variables. This implies that the sample size of 2138 observations (excluding the cases with missing data) could support up to about 11 variables $\left(2^{11}=2048,2^{12}=4096\right)$. Given that this is an empirical 
recommendation and $\mathrm{CA}$ is not an inferential technique, such power considerations are secondary and may be exceeded as long as a well-defined clustering scheme is obtained. An attempt to minimize the number of clustering variables by running Principal Components Analysis (PCA) rendered many Principal Components (PCs) with poor interpretation.

Hierarchical CA with Ward's linkage method (which tends to form distinct cluster; Milligan 1980) was run on the differences of normative and descriptive scores with the squared Euclidean distance as the recommended distance metric (Hair et al. 2009; Everitt et al. 2011). Of the CA schemes that were computed, the four-cluster solution was suggested by the dendrogram (not shown) and gave the most meaningful clustering results. The size and composition of the four clusters is shown in Table 5.

Two larger clusters (Clusters 1 and 2, each containing a bit over one third of the cases) and two smaller clusters (Clusters 3 and 4, each containing about one seventh of the cases) were obtained. The results of a Discriminant Analysis that was run to validate the clustering scheme (not shown) classified $83.2 \%$ of the cases in the correct cluster, with better classification results in the smaller clusters.

A pictorial representation of the composition of each cluster is shown in the bar chart of Figure 3 . The percentage of civil personnel decreased from Cluster 1 to Cluster 4 . Cluster 2 contained the smallest percentage of officers. Cluster 3 contained the biggest percentage of non-commissioned officers. Finally, Cluster 4 contained the biggest percentage of commissioned officers and veterans.

The centroid values of the difference variables used for clustering are shown in Table 6 . The last column of Table 6 displays the statistical significance of either an ANOVA or a Welch test (depending on the results of a Levene's test of homogeneity of variance), confirming that all clustering variables were well differentiated among the clusters.

The following observations are made on the nature of the clusters:

1. Cluster 1 was the cluster of the politically non-aligned, since its profile was dominated by the big difference between the normative and descriptive ratings of the BLUNT and NONPARTISAN variables. Respondents in this cluster thought that appearance is as important as it should be (evidenced by the near zero value of the APPEAR difference variable). Willingness to cooperate with the political leadership was regarded as playing a more important role than it deserved (as shown by the -1.726 score of the COOPERAT variable difference).

2. Cluster 2 was the religious cluster, as it was relatively similar to Cluster 1, but for a couple of important differences: (a) respondents thought that being nonpartisan was afforded appropriate importance during the promotion process (evidenced by the near zero value of the NONPARTISAN difference); (b) compared to Cluster 1, respondents in this cluster thought that being religious should be a more important trait for selecting leadership (as shown by the RELIGIOUS difference being equal to 2.074, up from 0.565 in Cluster 1). As with the previous cluster, the willingness to cooperate with political leaders was viewed as playing too much of a role in promotions (COOPERAT difference equal to -1.859).

3. Cluster 3 was very different from the previous two clusters, as all difference variables were near zero. Thus, it was regarded as the cluster of the authority-oriented conformists, i.e. the group of respondents who thought that all was well with promotions (toeing the official line).

4. Finally, Cluster 4 could be thought of as the cluster of dissatisfied/discontented/nonconformist respondents, who felt that most traits did not receive the attention they should when promoting top leaders for the armed and security forces. Almost all traits (including bluntness, nonpartisanship meritocracy, impartiality, morale, being religious, character, crisis management skills and experience, with a normative minus descriptive rating difference over 3) were regarded as brushed aside during promotions. Members of this cluster also thought that being cooperative with the political leadership was taken into consideration more than it should, but to a lesser extent than Clusters 1 and 2.

Four scatterplots are now examined that are similar to Figure 2, but depict the average score of each descriptive trait versus the average score of each normative trait within each cluster.

Figure 4 shows the scatterplot for Cluster 1, the politically non-aligned respondents. As in Figure 2, the location of the cooperation with the political leadership point (at the upper left of the scatterplot) shows that this was the only trait that respondents thought played a bigger role during promotions than it should. The personal appearance point (at the lower left of the scatterplot) was practically on the dotted slope, showing that appearance was correctly regarded as moderately important during promotions. Being religious was also located near the slope line. NATO and other international experience, and communication skills were regarded as traits that should be taken into consideration to a greater extent during promotions. As in Figure 2, many of the other points that clustered at the lower right of the scatterplot (especially being blunt and non-partisan), indicated skills that respondents thought should be regarded as more important during promotions. All in all, Cluster 1 was the most similar to the overall sample average.

Figure 5 relates the average descriptive and normative scores of Cluster 2 that contained the religious respondents. These respondents agreed with the respondents of the previous cluster that cooperation (at the upper left of the scatterplot) was a trait that was taken into consideration more than it should. Appearance and being non- 
partisan were near the slope line, so religious respondents considered them issues that were afforded about the right amount of attention during promotions. NATO and other international experience as well as communication skills were regarded as somewhat overlooked during promotions. Being religious was located at the bottom center of the scatterplot, showing that the respondents of Cluster 2 thought that faith in God should be considered more important in promotions. The rest of the rating variables were located at the lower right of the scatterplot, indicating traits (especially bluntness) that should be regarded as much more important traits during promotions.

Figure 6 shows that all the average descriptive and normative score pairs of Cluster 3 were located near the slope line. Thus, it was confirmed as the cluster of respondents who were conformist in the sense that they supported the official line, thinking that all was well with the way promotions of top leadership were done in the armed and security forces.

Finally, Figure 7 shows the scatterplot for Cluster 4 that contained the nonconformist respondents. Cooperation was far above the slope line, with all other scores far below the slope line, confirming that the respondents of Cluster 4 were very critical of the way leadership was selected in the armed and security forces. The assessment of the trait of bluntness was particularly impressive: Cluster 4 respondents gave it a normative score of almost 5 (maximum), and a descriptive score of almost 1 (minimum).

\subsection{Discussion}

Looking at the overall picture, bluntness was the trait with the biggest difference between its normative and descriptive rating, followed by meritocracy and impartiality (Table 3 and Figure 1). Respondents thought that these leadership traits were erroneously regarded as less important during promotions in the armed and security forces. On the other hand, being willing to cooperate with the political leadership was the only trait for which respondents thought that it mattered more than it should.

As regards groups of like-minded personnel, Cluster Analysis revealed that $86.3 \%$ of the respondents (Clusters 1, 2 and 4) thought that promotions failed to consider the appropriate leadership traits. On the other hand, $13.9 \%$ of the respondents (Cluster 4 ) disagreed very strongly with how the different traits counted during promotions in the armed and security forces. Respondents who thought that all was well, and agreed with the way things are, were a mere $13.7 \%$ of the total (Cluster 3 ).

These results must be taken into consideration by the armed and security forces, if they wish to impart the leadership promotion process with more impartiality. If they do so, they should know that the majority of armed and security forces personnel will likely be in agreement; in fact, the nonconformist respondents of Cluster 4 , including many commissioned officers and veterans, will be motivated to act as their change champions.

\section{Conclusions}

This research discovered four personnel clusters within the armed and security forces of Greece: politically non-aligned; religious; authority-oriented conformist; and dissatisfied nonconformist. Individuals in these clusters share similar perceptions as to the character and personality traits that play an important role during the promotion of high-ranking officers to leader of the armed and security forces. The discovery of these clusters brings to mind the "energy tribes" that have been discussed by Thomson (1987) and Caputo (2009): distinct societal groups with different political and personal world views, which imply different attitudes, beliefs and solutions to many global energy and environmental problems. Stemming from anthropology and cultural theory, these findings imply that members of the different personnel clusters (or tribes) may view important disputes in their profession from different premises and will tend to disagree. If the objective were to maintain the morale of personnel, this research offers the following piece of advice: use "messy" or "clumsy" sets of traits to promote leaders, i.e. a mix of traits that distills elements of experience and wisdom from all personnel tribes (Thomson 1987).

Turning to suggestions for further research, this work has limited external validity because it polled only the Greek army and security forces. Similar research on personality trait perceptions in the armed forces of other countries could extend and generalize our findings. Furthermore, this research did not examine the objectivity of traits nor their association with success. Traits may be inherited (Allen 1998) or environment and situation specific (Horner 1997), and may not be good predictors of success (Asrar-ul-Haq \& Anwar 2018; Pierce \& Newstrom, 2006). Ingrained characteristics (that may not be easily changed) may be less instrumental for success than traits that may be amended and developed (Gayton \& Kehoe 2015; Doty \& Sowden 2009). Also, the political leadership may exert a direct (perhaps undue) influence on the promotions to leader of the armed and security forces. More research may elucidate these points. Future studies could even use data from leaders' self-assessment of their own leadership. Finally, Wong et al. (2003) highlighted the lack of studies examining the role of gender in military leadership, a question that was also beyond the scope of this research.

\section{Acknowledgments}

The authors thank Drs. T. Nadasdi and S. Sinclair for Spell Check Plus (http://spellcheckplus.com) that was used for proofing the entire manuscript. 


\section{References}

Allen, D. W. (1998). How nurses become leaders: Perceptions and beliefs about leadership development. Journal of Nursing Administration. 28(9), 15-20. doi: 10.1097/00005110-199809000-00005, https://doi.org/10.1097/00005110-199809000-00005.

Asrar-ul-Haq, M., \& Anwar, S. (2018). The many faces of leadership: Proposing research agenda through a review of literature. Future Business Journal. 4, 179-188. doi: 10.1016/j.fbj.2018.06.002, https://doi.org/10.1016/j.fbj.2018.06.002.

Begeç, S. (2013). Selection and training of leaders in the Turkish Armed Forces. International Review of Management and Marketing. 3(4), 226-231. Available: https://www.econjournals.com/index.php/irmm/article/view/612 (February 1, 2020).

Bennis, W. G. \& Nanus, B. (1985). Leaders: The Strategies for Taking Charge. New York: Harper \& Row. doi: 10.1177/019263658707150021, https://doi.org/10.1177/019263658707150021.

Boe, O. \& Bang, H. (2017). The big 12: The most important character strengths for military officers. Athens Journal of Social Sciences. 4(2). doi: 10.30958/ajss.4-2-4, https://doi.org/10.30958/ajss.4-2-4.

Boe, O. \& Holth, T. (2015). The Relationship between Developmental Leadership, the Results of Leadership and Personality Factors. Procedia Economics and Finance. 26, 849-858. doi: 10.1016/S2212-5671(15)00892-8, https://doi.org/10.1016/S2212-5671(15)00892-8.

Caputo, R. (2008). Hitting the Wall: A Vision of a Secure Energy Future. Morgan \& Claypool Publishers, (Chapter 6). $\quad$ doi: 10.2200/S00124ED1V01Y200805EGY003, https://www.morganclaypool.com/doi/abs/10.2200/S00124ED1V01Y200805EGY003.

Day D. V., Fleenor J. W., Atwater L. E., Sturm R. E., \& Mckee R. A. (2014). Advances in leader and leadership development: A review of 25 years of research and theory. The Leadership Quarterly. 25, 63-82. doi: 10.1016/j.leaqua.2013.11.004, https://doi.org/10.1016/j.leaqua.2013.11.004.

Doty, J. \& Sowden, W. (2009). Competency vs. character? It must be both! Military Review. 89(6), 69-76. Available:

https://sites.lsa.umich.edu/waltersowden/wpcontent/uploads/sites/186/2014/10/doty_sowden_2009_competencyvscharacter_mr_pdf (February 1, 2020).

Erasmus, W. D. \& Uys, F. (2012). Military leadership development: A model for the SA national defense force. South African Journal of Military Studies. 40(1), 95-116. doi: 10.5787/40-1-986, https://doi.org/10.5787/401-986.

Everitt, B. S., Landau, S., Leese, M., \& Stahl, D. (2011). Cluster analysis. (5th ed.). King's College London, UK: Wiley Series in Probability and Statistics.

Fairholm, M. R. (2002). Defining leadership: A review of past, present, and future ideas. Centre for Excellence in Municipal Ideas, Monograph Series MSO2. Available: http://www.strategies-for-managingchange.com/support-files/definingleadershipreview.pdf (February 1, 2020).

Formann, A. K. (1984). Die Latent-Class-Analyse: Einführung in die Theorie und Anwendung. Weinheim, Germany: Beltz. OCLC Number: 680132951.

Gayton, S. D. \& Kehoe, E. J. (2015). Character Strengths and Hardiness of Australian Army Special Forces Applicants. Military Medicine. 180(8), 857-862. doi: 10.7205/MILMED-D-14-00527, https://doi.org/10.7205/MILMED-D-14-00527.

Hair, J. F., Black, W. C., Babin, B. J., \& Anderson, R. E. (2009). Multivariate Data Analysis. (7th ed.). New Jersey, USA: Prentice Hall.

Hannah, S. T. \& Sowden, W. J. (2012). Leadership in the Profession of Arms. In M. G. Rumsey (Ed.), Oxford library of psychology, The Oxford handbook of Leadership (pp. 291-310). New York, NY, US: Oxford University $\quad$ Press. doi: 10.1093/oxfordhb/9780195398793.001.0001, https://dx.doi.org/10.1093/oxfordhb/9780195398793.001.0001.

Hardaway, M. J. (2008). Strategic Leader Development for a 21st Century Army. School of Advanced Military Studies United States Army Command and General Staff College Fort Leavenworth, Kansas. doi: 10.21236/ada484881.

Available: https://pdfs.semanticscholar.org/c928/fbb687eb64e65a3799721d2756ff4146739d.pdf?_ga=2.132044940.20 92864534.1580556225-692798321.1580556225 [February 1, 2020).

Hogan, R., \& Kaiser, R. B. (2005). What We Know About Leadership. Review of General Psychology. 9(2), 169180. doi: 10.1037/1089-2680.9.2.169, https://doi.org/10.1037/1089-2680.9.2.169.

Horner, M. (1997). Leadership theory: Past, present and future. Team Performance Management: An International Journal, 3(4), 270-287. doi: 10.1108/13527599710195402, https://doi.org/10.1108/13527599710195402.

Ivancevich, J.M., Konopaske, R., \& Matteson, M.T. (2011). Organizational behavior and management. (9th ed.). New York, NY: McGraw-Hill Irwin.

Johnson, C. H. (2014). Reflections on leadership. Naval War College Review. 67(1), 135-144. Available: https://digital-commons.usnwc.edu/cgi/viewcontent.cgi?article=1251\&context=nwc-review (February 1, 2020). 
Keller, J. (2014). Military Leadership and Leaders. ENDC Proceedings. 19, 26-45. Available: https://www.ksk.edu.ee/wp-content/uploads/2014/12/KVUOA_Toimetised_19_03_keller.pdf (February 1, 2020).

Khan, Z. A., Nawaz, A., \& Khan, I. (2016). Leadership Theories and Styles: A Literature Review. Journal of Resources Development and Management. An International Peer-Reviewed Journal. Available: https://iiste.org/Journals/index.php/JRDM/article/view/28481 (February 2, 2020).

Milligan, G. W. (1980). An examination of the effect of six types of error perturbation on fifteen clustering algorithms. Psychometrika. 45(3), 325-342. doi: 10.1007/BF02293907, https://doi.org/10.1007/BF02293907.

Mooi, E., \& Sarstedt, M. (2011). A Concise Guide to Market Research: The Process, Data, and Methods Using IBM SPSS Statistics. Berlin/Heidelberg, Germany: Springer. doi: 10.1007/978-3-642-12541-6, https://doi.org/10.1007/978-3-642-12541-6.

Navy Department (1913). Leadership - Military character. Bureau of Navigation. Washington, DC Government Printing Office (pp 2-32). Available: https://books.googleusercontent.com/books/content?req=AKW5Qad8R50jQhuEkejz0E1E1xShj75yVbnS72RSfv9lkbHA3Aai1516qCFpx2nNLnCAEldMABn8ag32JPOoEp0Yupy8vYwGyvjcjPjiugW1ez2YhKGZ8qSNxgz6n1Jla0hBlWBjr9qLai7sCgRslYCso0joXfLwiTbyJvnwztmBcEPnSbaiVFhWJM5Av1rH4SPNPwlDkL3rmfpTY5XICHr8SVyat9DOBmysHVqITPtaB9O_hU7ONPYoXRIo7IOaAJUog1LGvw69vP1nPR8UyPAEwhQA (February 2, 2020).

Nichols, A. L. \& Cottrell, C. A. (2014). What do people desire in their leaders? The role of leadership level on trait desirability. The Leadership Quarterly. 25, 711-729. doi: 10.1016/j.leaqua.2014.04.001, https://doi.org/10.1016/j.leaqua.2014.04.001.

Nickels, W. G., McHugh, J. M., \& McHugh, S. M. (2010). Understanding Business. (9th ed.). McGraw- Hill/Irwin, NY.

Northouse, P. G. (2016). Leadership - Theory and Practice. (7th ed.). SAGE Publications, Inc (Chapter 1).

Özlen, M. K. \& Zukic, A. (2013). A Descriptive Study on the Military Leadership. International Journal of Academic Research in Business and Social Sciences. 3(7), 707-719. doi: 10.6007/IJARBSS/v3-i7/102, http://dx.doi.org/10.6007/IJARBSS/v3-i7/102.

Pierce, J. L. \& Newstrom, J. W. (2006). Leaders \& the leadership process: Readings, self-assessments \& applications. Boston: McGraw-Hill Irwin.

Reed, G. E. \& Bullis, C. R. (2009). The impact of destructive leadership on senior military officers and civilian employees. Armed Forces \& Society. 36(1), 5-18. doi: 10.1177/0095327X09334994, https://doi.org/10.1177/0095327X09334994.

Rost, C. J. (2013). Leadership Development in the New Millennium. Journal of Leadership and Organizational Studies. 1(1), 91-110. doi: 10.1177/107179199300100109, https://doi.org/10.1177/107179199300100109.

Singh, J. P., Tiwary, D., \& Mishra, S. N. (2015). A Conceptual Approach to Officer Selection and Officer Like Qualities. International Journal of Scientific and Research Publications. 5(10). Available: http://www.ijsrp.org/research-paper-1015/ijsrp-p4650.pdf (February 1, 2020).

Thomson, M. (1987). Among the energy tribes: A cultural framework for the analysis and design of energy policy. Policy Sciences. 17(3), 321-329. doi: 10.1007/BF00138710, https://doi.org/10.1007/BF00138710.

US Army (1965). Military leadership. Headquarters, Department of the Army. Washington, DC, November 1965. Field Manual No. 22-100. Available: https://www.bits.de/NRANEU/others/amd-us-archive/FM22100\%2865\%29.pdf (February 1, 2020).

US Army (2006). Army Leadership Competent, Confident, and Agile. Headquarters, Department of the Army. Washington, DC, 12 October 2006. Field Manual No. 6-22. Available: https://www.armywriter.com/fm622.pdf (February 1, 2020).

Ulmer Jr., W. F. (1998). Military leadership into the 21st century: Another "bridge too far?". Journal PARAMETERS, 40(4), 135-155. Available: https:/www.semanticscholar.org/paper/Military-Leadershipinto-the-21st-Century\%3A-Another-Ulmer/b0b12d1f45d444c6fc629e2c6ce65cd650e56fac (February 1, 2020).

Wisecarver, M., Schneider, R., Foldes, H., Cullen, M., \& Zbylut, M. R. (2011). Knowledge, Skills, and Abilities for Military Leader Influence. US Army Research Institute for the Behavioral and Social Sciences. Available: https://apps.dtic.mil/dtic/tr/fulltext/u2/a540059.pdf (February 1, 2020).

Wong, L., Bliese, P., \& McGurk, D. (2003). Military leadership: A context specific review. The Leadership Quarterly. 14, 657-692. doi: 10.1016/j.leaqua.2003.08.001, https://doi.org/10.1016/j.leaqua.2003.08.001.

Zaccaro, J. S., Klimoski, J. R., \& Gade, A. P. (1999). Army Leadership in the 21st Century: A Proposed Research Framework. US Army Research Institute for the Behavioral and Social Sciences. Available: http://citeseerx.ist.psu.edu/viewdoc/download?doi=10.1.1.870.7691\&rep=rep1\&type=pdf (February 1, 
2020).

Zaccaro, S. J., Kemp, C., \& Bader, P. (2004). Leader Traits and Attributes. In Antonakis, J. Cianciolo, A. T. \& Sternberg, R. J. (Eds.). The Nature of Leadership. Thousand Oaks, CA: Sage.

John A. Paravantis holds a M.Sc. and Ph.D. from Northwestern University and is an Associate Professor in the Department of International and European Studies of the University of Piraeus. Dr. Paravantis uses multivariate statistics, econometric modeling and optimization to research global technology systems and their environmental and geopolitical implications.

Nikoletta V. Kontoulis holds a M.Sc. and is a Ph.D. candidate in the Department of International and European Studies of the University of Piraeus. In her doctoral research, Ms. Kontoulis constructs a quantitative energy security index to examine geopolitics since 1970. Ms. Kontoulis has also published on fuel poverty.

Ioanna Iliadi is a professional journalist specializing in defense and working in ArmyVoice.gr. She holds a M.A. in Journalism and is a Guest Lecturer in the European Communication Institute. Her research is on social media and the military doctrine.

Table 1. Variable names and definitions

\begin{tabular}{|r|l|}
\hline \multicolumn{2}{|c|}{ Professional affiliation labels } \\
\hline OFFICER & officer \\
\hline NCOFFICER & noncommissioned officer \\
\hline VETERAN & veteran \\
\hline CECURITY & security force personnel \\
\hline \multicolumn{2}{|c|}{ Leadership trait ratings } \\
\hline COMMSKIL & Effective communication skills \\
\hline NONPARTISAN & Nonpartisan during professional development \\
\hline CHARACTER & Integrity \\
\hline NATOINT & NATO and international experience \\
\hline IMPARTIAL & Impartial treatment of colleagues \\
\hline BLUNT & Posing problems bluntly \\
\hline CRISESMAN & Crisis management skills \\
\hline STRATEG & Strategic, tactical and operational proficiency \\
\hline MERITOCR & Meritocracy in management \\
\hline EXPERIENC & Experience with all administration levels \\
\hline COOPERAT & Close cooperation with political leadership \\
\hline PERCEPT & Perception and good environmental awareness \\
\hline APPEAR & Appearance \\
\hline MORALE & High national morale \\
\hline RELIGIOUS & Religious/Faith in God \\
\hline
\end{tabular}

Table 2. Responses by gender and professional affiliation (with row percentages)

\begin{tabular}{r|c|c|c|c|}
\multicolumn{1}{c}{} & \multicolumn{1}{c}{ Male } & $\%$ & \multicolumn{1}{c}{ Female } & $\%$ \\
\cline { 2 - 5 } 1-OFFICER & 923 & 97.47 & 24 & 2.53 \\
\cline { 2 - 5 } 2-NCOFFICER & 512 & 95.88 & 22 & 4.12 \\
\cline { 2 - 5 } 3-VETERAN & 516 & 97.18 & 15 & 2.82 \\
\cline { 2 - 5 } 4-SECURITY & 74 & 91.36 & 7 & 8.64 \\
\cline { 2 - 5 } 5-CIVIL & 539 & 88.51 & 70 & 11.49 \\
Total & 2564 & 94.89 & 138 & 5.11
\end{tabular}


Table 3. Average normative and descriptive trait ratings (sorted in decreasing normative rating)

\begin{tabular}{rccc|} 
& $\begin{array}{c}\text { Average } \\
\text { rating } \\
\text { (normative) }\end{array}$ & $\begin{array}{c}\text { Average } \\
\text { rating } \\
\text { (descriptive) }\end{array}$ & $\begin{array}{c}\text { Difference } \\
\text { (normative-descriptive) }\end{array}$ \\
\cline { 2 - 4 } CRISESMAN & 4.91 & 2.87 & 2.06 \\
\cline { 2 - 4 } CHARACTER & 4.90 & 2.73 & 2.18 \\
\cline { 2 - 4 } PERCEPT & 4.84 & 2.99 & 1.86 \\
\cline { 2 - 4 } MERITOCR & 4.83 & 2.47 & 2.37 \\
\cline { 2 - 4 } STRATEG & 4.77 & 2.97 & 1.80 \\
\cline { 2 - 4 } BLUNT & 4.76 & 2.02 & 2.76 \\
\cline { 2 - 4 } IMPARTIAL & 4.73 & 2.40 & 2.34 \\
\cline { 2 - 4 } MORALE & 4.67 & 2.78 & 1.90 \\
\cline { 2 - 4 } EXPERIENC & 4.42 & 2.68 & 1.75 \\
\cline { 2 - 4 } NONPARTISAN & 4.41 & 3.06 & 1.37 \\
\cline { 2 - 4 } COMMSKIL & 4.08 & 2.84 & 0.96 \\
\cline { 2 - 4 } NATOINT & 3.97 & 3.01 & 1.37 \\
\cline { 2 - 4 } RELIGIOUS & 3.82 & 2.46 & 0.43 \\
\cline { 2 - 4 } APPEAR & 3.27 & 2.83 & -1.44 \\
\cline { 2 - 4 } COOPERAT & 3.05 & 4.46 &
\end{tabular}

Table 4. Average trait ratings per rank and professional affiliation with significance (p) of appropriate test (ANOVA or Welch, following Levene's test of homogeneity of variances)
1-OFFICER
2-
3-VETERAN
4-SECURITY
5-CIVIL
$\mathrm{p}$

Aver. Aver. Aver. Aver. Aver. Aver. Aver. Aver. Aver. Aver. norm. desc.

\begin{tabular}{|c|c|c|c|c|c|c|c|c|c|c|c|c|}
\hline & & \multirow[b]{2}{*}{2.90} & \multirow[b]{2}{*}{4.29} & \multirow{2}{*}{\multicolumn{2}{|c|}{\begin{tabular}{l|l}
2.82 & 4.15
\end{tabular}}} & & & \multirow{2}{*}{\multicolumn{2}{|c|}{0.0000}} & \multirow[b]{2}{*}{0.4885} \\
\hline COMMSKIL & 4.10 & & & & & & & & & & & \\
\hline NONPARTISAN & 4.39 & 2.89 & 4.43 & 3.41 & 4.38 & 3.11 & 4.58 & 3.24 & 4.42 & 2.93 & 0.5335 & 0.0000 \\
\hline CHARACTER & 4.89 & 2.72 & 4.89 & 2.75 & 4.92 & 2.88 & 4.89 & 2.84 & 4.90 & 2.58 & 0.8210 & 0.0035 \\
\hline NATOINT & 3.88 & 3.01 & 3.98 & 3.02 & 4.06 & 2.89 & 3.95 & 3.00 & 4.02 & 3.11 & 0.0122 & 0.0727 \\
\hline IMPARTIAL & 4.65 & 2.39 & 4.87 & 2.34 & 4.79 & 2.54 & 4.78 & 2.46 & 4.68 & 2.35 & 0.0000 & 0.1142 \\
\hline BLUNT & 4.77 & 1.85 & 4.75 & 2.22 & 4.80 & 2.06 & 4.66 & 2.17 & 4.74 & 2.04 & 0.2856 & 0.0002 \\
\hline CRISESMAN & 4.91 & 2.81 & 4.89 & 2.93 & 4.92 & 2.91 & 4.90 & 2.79 & 4.92 & 2.86 & 0.7016 & 0.4064 \\
\hline STRATEG & 4.74 & 2.92 & 4.72 & 3.02 & 4.81 & 3.01 & 4.76 & 2.97 & 4.82 & 2.99 & 0.0306 & 0.5541 \\
\hline MERITOCR & 4.83 & 2.48 & 4.85 & 2.48 & 4.85 & 2.57 & 4.85 & 2.40 & 4.77 & 2.37 & 0.0737 & 0.1390 \\
\hline EXPERIENC & 4.42 & 2.66 & 4.45 & 2.81 & 4.53 & 2.70 & 4.18 & 2.46 & 4.32 & 2.62 & 0.0001 & 0.0739 \\
\hline COOPERAT & 3.12 & 4.58 & 2.67 & 4.29 & 3.21 & 4.42 & 3.11 & 4.58 & 3.12 & 4.43 & 0.0000 & 0.0003 \\
\hline PERCEPT & 4.85 & 2.99 & 4.83 & 2.96 & 4.86 & 3.08 & 4.80 & 2.96 & 4.82 & 2.92 & 0.6972 & 0.3099 \\
\hline APPEAR & 3.51 & 2.78 & 3.16 & 2.92 & 3.61 & 2.81 & 3.03 & 2.63 & 2.72 & 2.89 & 0.0000 & 0.1548 \\
\hline MORALE & 4.68 & 2.73 & 4.67 & 2.74 & 4.72 & 2.90 & 4.67 & 2.67 & 4.61 & 2.78 & 0.2190 & 0.2059 \\
\hline RELIGIOUS & 3.78 & 2.34 & 4.09 & 2.59 & 3.95 & 2.55 & 3.53 & 2.43 & 3.55 & 2.45 & 0.0000 & 0.0153 \\
\hline
\end{tabular}

Table 5. Size and composition of clusters (with row percentages)

\begin{tabular}{rcccccc} 
& CLUST1 & CLUST2 & CLUST3 & CLUST4 & Total \\
size & 789 & 758 & 293 & 298 & 2138 \\
MALE & $(36.9 \%)$ & $(35.5 \%)$ & $(13.7 \%)$ & $(13.9 \%)$ & $(100 \%)$ \\
\cline { 2 - 6 } & $95.56 \%$ & $96.44 \%$ & $93.86 \%$ & $95.3 \%$ & $100 \%$ \\
\cline { 2 - 5 } 1-OFFICER & 316 & 244 & 97 & 124 & 781 \\
& $(40.6 \%)$ & $(31.2 \%)$ & $(12.4 \%)$ & $(15.9 \%)$ & $(100 \%)$ \\
\cline { 2 - 5 } 2-NCOFFICER & 113 & 174 & 84 & 55 & 426 \\
& $(26.5 \%)$ & $(40.9 \%)$ & $(19.7 \%)$ & $(12.9)$ & $(100 \%)$ \\
\cline { 2 - 5 } 3 3-VETERAN & 136 & 145 & 50 & 66 & 397 \\
& $(34.3 \%)$ & $(36.5 \%)$ & $(12.6 \%)$ & $(16.6 \%)$ & $(100 \%)$ \\
\cline { 2 - 5 } $4-S E C U R I T Y$ & 21 & 24 & 8 & 8 & 61 \\
& $(34.4 \%)$ & $(39.3 \%)$ & $(13.1 \%)$ & $(13.1 \%)$ & $(100 \%)$ \\
\cline { 2 - 5 } & 203 & 171 & 54 & 45 & 473 \\
& $(10.2 \%)$ & $(11.4 \%)$ & $(9.5)$ & $(100 \%)$
\end{tabular}


Table 6. Centroid values of clustering variables (normative minus descriptive ratings) with significance (p) of appropriate test (ANOVA or Welch, following Levene's test of homogeneity of variances)

\begin{tabular}{|c|c|c|c|c|c|}
\hline \multirow{3}{*}{$\begin{array}{l}\text { COMMSKIL difference } \\
\text { NONPARTISAN difference }\end{array}$} & CLUST1 & CLUST2 & CLUST3 & CLUST4 & $\mathrm{p}$ \\
\hline & 1.049 & 1.338 & 0.184 & 2.748 & 0.000 \\
\hline & 3.019 & -0.397 & -0.147 & 3.423 & 0.000 \\
\hline \multirow{2}{*}{$\begin{array}{r}\text { CHARACTER difference } \\
\text { NATOINT difference }\end{array}$} & 2.455 & 2.487 & 0.123 & 3.081 & 0.000 \\
\hline & 0.981 & 0.883 & -0.044 & 1.983 & 0.000 \\
\hline \multirow{2}{*}{$\begin{array}{l}\text { IMPARTIAL difference } \\
\text { BLUNT difference }\end{array}$} & 2.641 & 2.625 & 0.167 & 3.336 & 0.000 \\
\hline & 3.289 & 2.996 & 0.181 & 3.792 & 0.000 \\
\hline \multirow{2}{*}{$\begin{array}{l}\text { CRISESMAN difference } \\
\text { STRATEG difference }\end{array}$} & 2.165 & 2.367 & 0.133 & 3.074 & 0.000 \\
\hline & 1.848 & 2.081 & 0.075 & 2.883 & 0.000 \\
\hline \multirow{2}{*}{$\begin{array}{l}\text { MERITOCR difference } \\
\text { EXPERIENC difference }\end{array}$} & 2.650 & 2.646 & 0.143 & 3.416 & 0.000 \\
\hline & 1.781 & 1.945 & 0.055 & 3.030 & 0.000 \\
\hline \multirow{2}{*}{$\begin{array}{l}\text { COOPERAT difference } \\
\text { VERSATIL difference }\end{array}$} & -1.726 & -1.859 & -0.266 & -1.094 & 0.000 \\
\hline & 1.962 & 2.140 & 0.072 & 2.903 & 0.000 \\
\hline \multirow{2}{*}{$\begin{array}{l}\text { APPEAR difference } \\
\text { MORALE difference }\end{array}$} & 0.041 & 0.354 & -0.058 & 2.024 & 0.000 \\
\hline & 1.772 & 2.347 & -0.021 & 3.285 & 0.000 \\
\hline RELIGIOUS difference & 0.565 & 2.074 & -0.089 & 3.107 & 0.000 \\
\hline
\end{tabular}

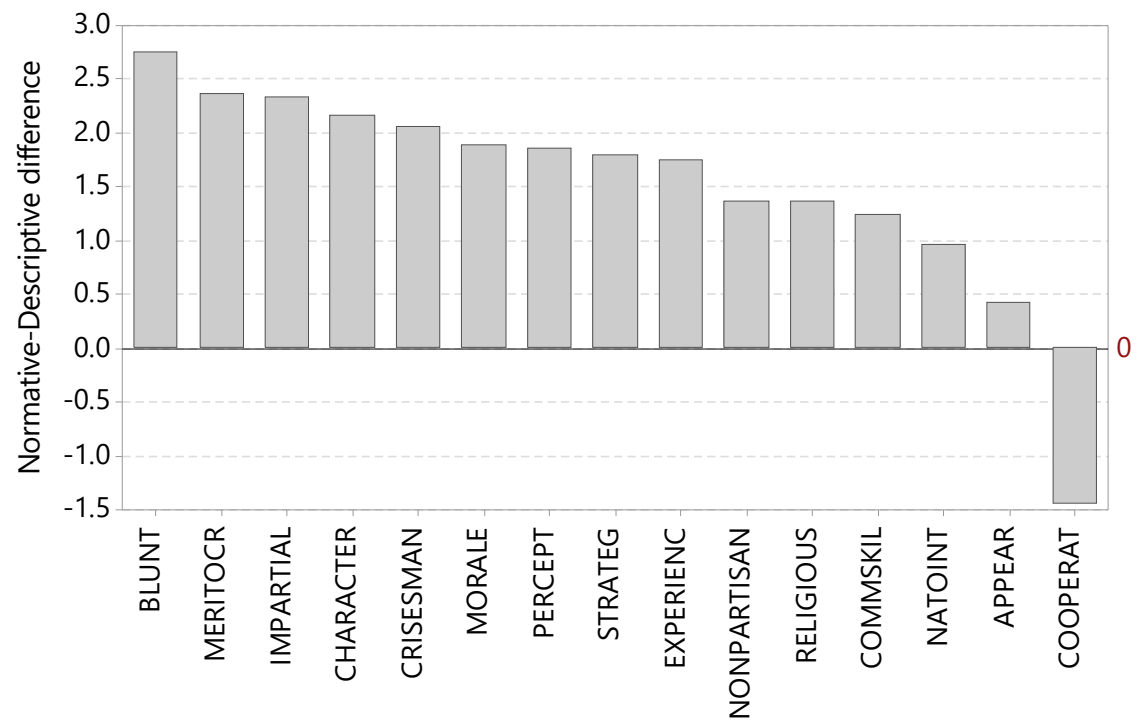

Figure 1. Bar chart of differences of normative minus descriptive average trait ratings 


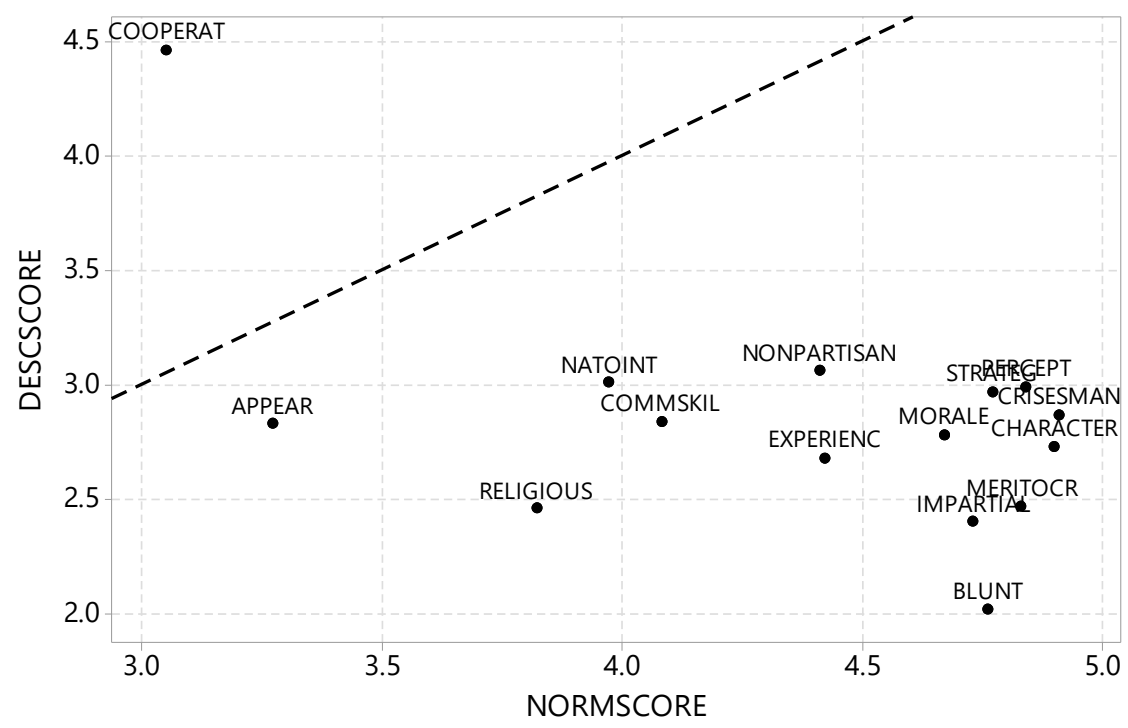

Figure 2. Scatterplot of descriptive (DESCSCORE) vs normative (NORMSCORE) average trait ratings (black dotted line shows 1:1 slope)

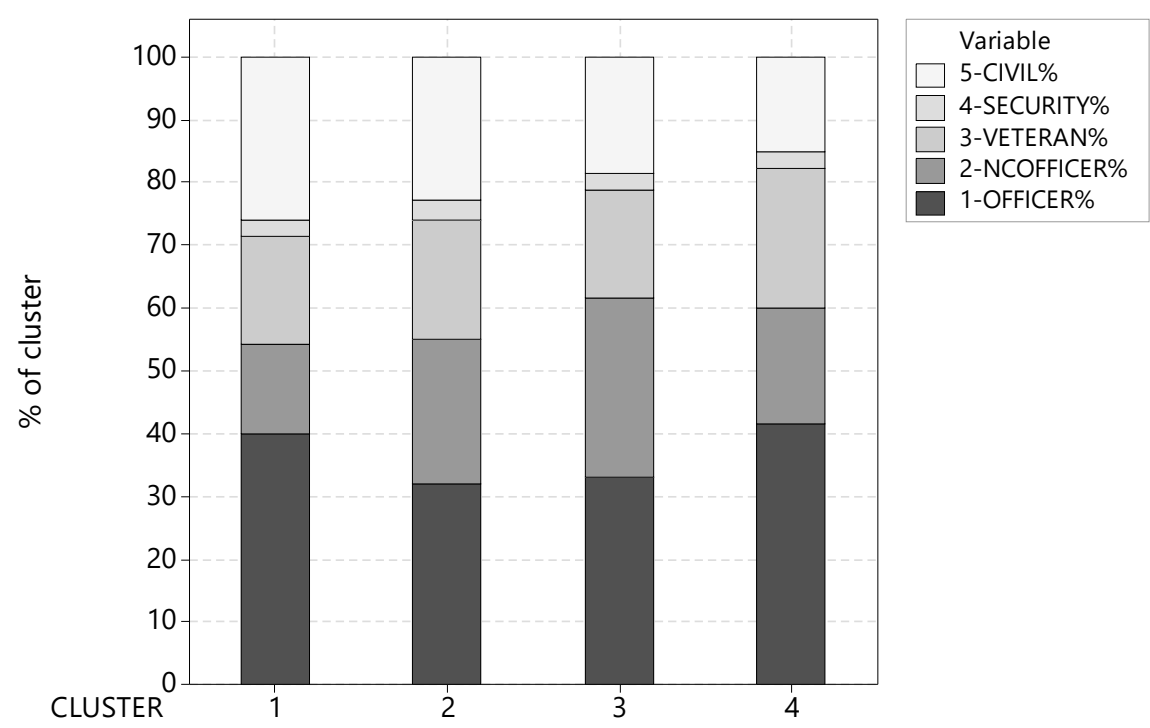

Figure 3. Bar chart showing the composition of the four clusters 


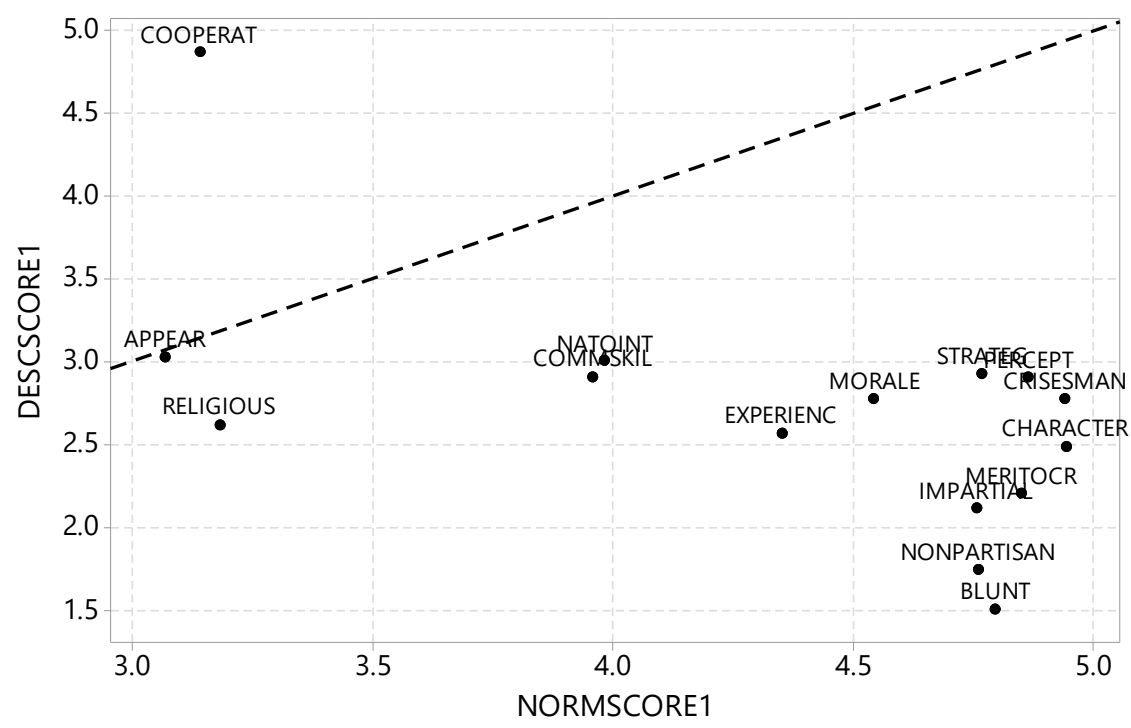

Figure 4. Scatterplot of descriptive (DESCSCORE1) vs normative (NORMSCORE1) average trait ratings for Cluster 1 (politically non-aligned)

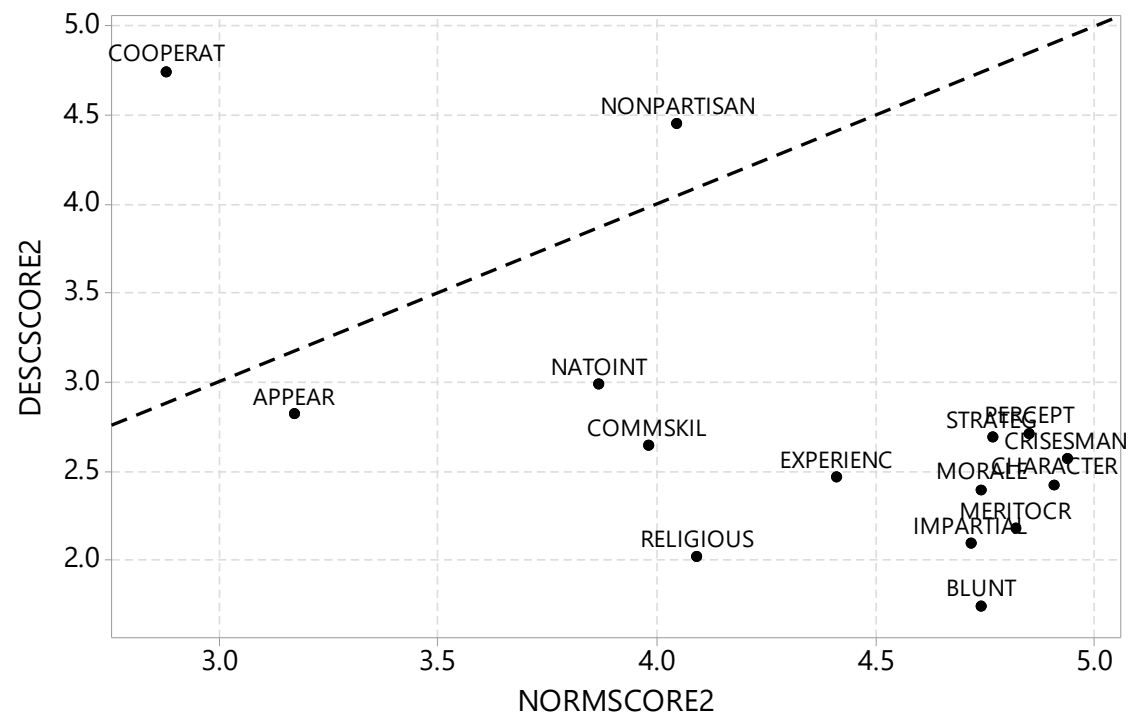

Figure 5. Scatterplot of descriptive (DESCSCORE2) vs normative (NORMSCORE2) average trait ratings for Cluster 2 (religious) 


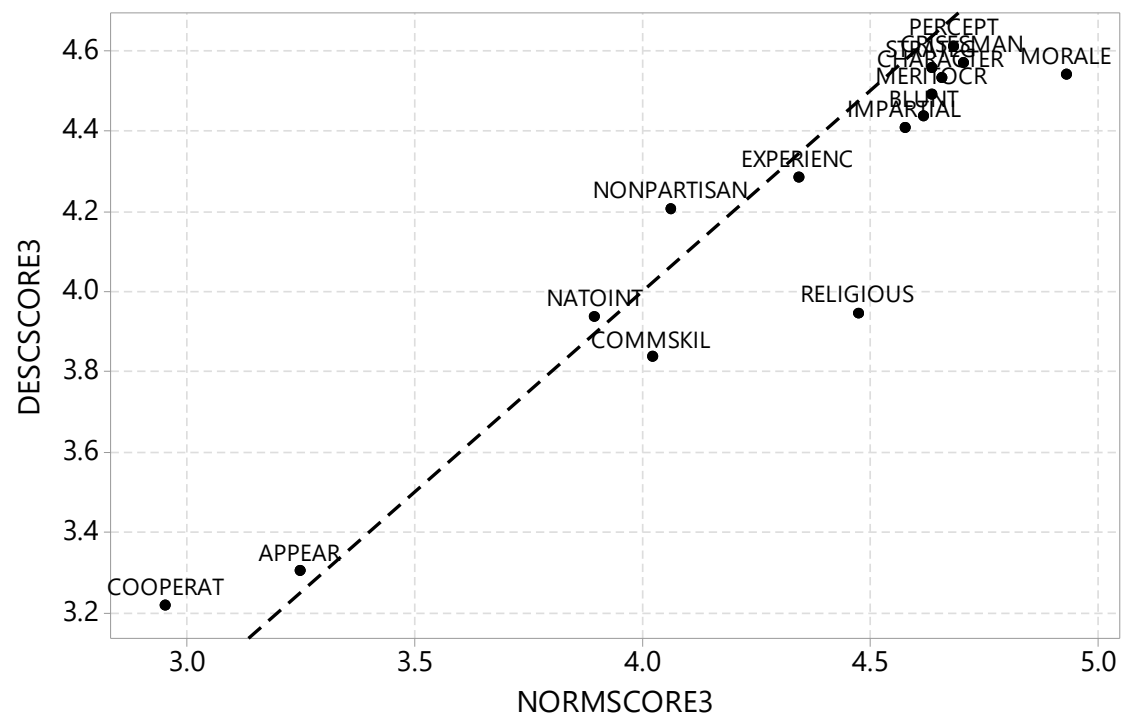

Figure 6. Scatterplot of descriptive (DESCSCORE3) vs normative (NORMSCORE3) average trait ratings for Cluster 3 (conformist)

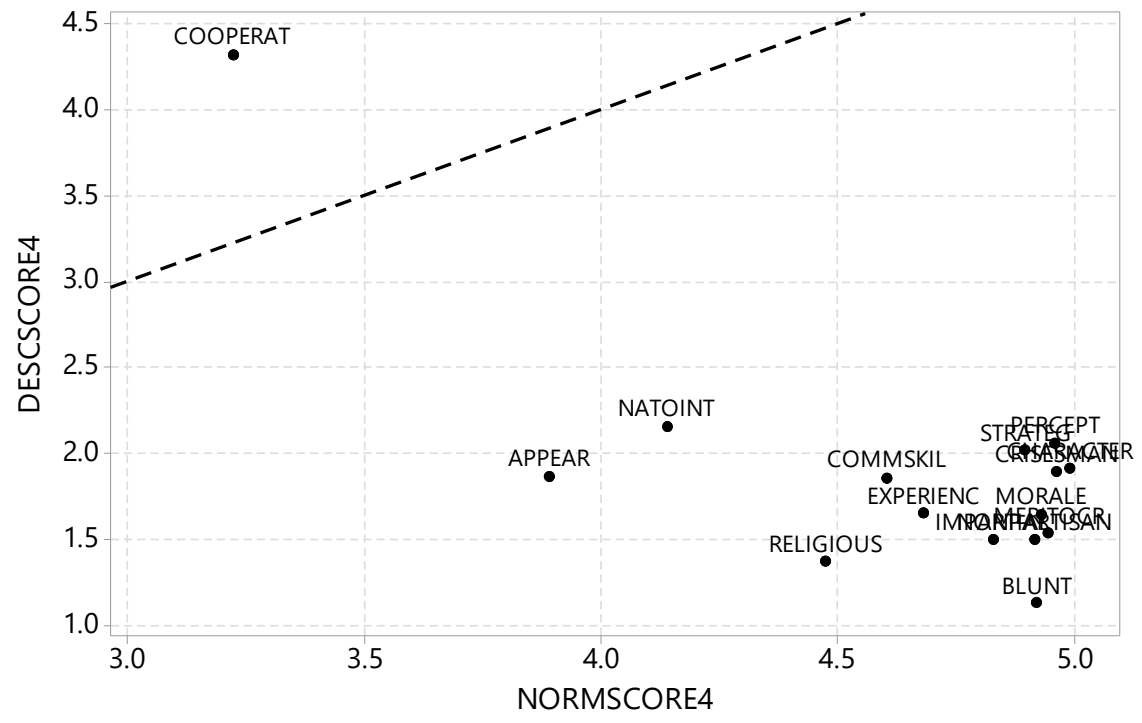

Figure 7. Scatterplot of descriptive (DESCSCORE4) vs normative (NORMSCORE4) average trait ratings for Cluster 4 (nonconformist) 